\title{
扫描古人类的蛋白质“条形码”，回答“我们从哪里来”
}

\author{
栗静舒 ${ }^{1,2}$
}

1. 中国科学院古脊椎动物与古人类研究所, 北京 100044 ;

2. 中国科学院脊椎动物演化与人类起源重点实验室, 北京 100044

E-mail: lijingshu@ivpp.ac.cn

\section{Scan the "bar code" provided by ancient proteins to know where we come from}

\author{
Jingshu $\mathrm{Li}^{1,2}$ \\ ${ }^{1}$ Institute of Vertebrate Paleontology and Paleoanthropology, Chinese Academy of Sciences, Beijing 100044, China; \\ ${ }^{2}$ Key Laboratory of Vertebrate Evolution and Human Origins of Chinese Academy of Sciences, Beijing 100044, China \\ E-mail: lijingshu@ivpp.ac.cn \\ doi: 10.1360/TB-2020-1023
}

蛋白质是构成人体生命的两种生物大分子之一, 另一 种是核酸. 其中, 核酸是传递遗传信息的载体, 而蛋白质 是生命体根据核酸信息记载的遗传图纸, 转译出来行使生 物功能的最基础结构. 蛋白质由 20 种氨基酸排列与折叠 而构成, 其“形成法则”倒映着遗传信息的编码规则, 同样 也蕴含着不同生命独特的 “条形码”. 随着相关研究成果的 陆续发表, 古蛋白质研究犹如一匹黑马, 闯人长久以来古 DNA 一枝独秀的分子古人类学的研究领域之中, 展现出 势不可挡的劲头.

同样保存了遗传密码的古蛋白质似乎比古 DNA 更加 稳定, 能够保存的时间更久, 留下来的概率也更大. 近年 来, 质谱技术对部分古人类遗骸蛋白质的测序分析, 已经 能够检验出一些古蛋白内氨基酸的排列规则, 并重建出部 分蛋白质的一级序列. 也就是说, 这种生物大分子能够经 受漫长地质埋藏过程的洗礼, 保存在矿化的骨骼组织内.

2019 年, 来自哥本哈根、西班牙的研究团队和中国学 者合作, 提取出了步氏巨猿的古蛋白质, 将人科成员的古 蛋白质保存年代提前到了距今 190 万年之久 ${ }^{[1]}$. 与之相比, 古 DNA 信息极容易被降解, 再先进的 DNA 测序手段也无 法检测出降解殆尽的信息, 于是迄今为止人类最古老的 DNA 证据, 也没有超过 43 万年 ${ }^{[2]}$. 同时, DNA 样品在埋 藏、获取和实验过程中很容易受到外源性 DNA 的污染, 这 些污染与原样品信息同时通过聚合酶链反应技术扩增而 放大, 对 DNA 鉴定结果有一定影响, 但是蛋白质是具有组 织特异性的功能性生物大分子, 在研究过程中可以据此排 除外源性的污染, 增加数据的准确性.
古蛋白质信息在人类骨骼鉴定方面，同样具有潜力. 通过在古人类腭骨遗骸中提取并辨识出古蛋白质的单个 氨基酸变异, 中国科学院陈发虎团队 ${ }^{[3]}$ 在 2019 年找到并命 名了来自宁夏的丹尼索瓦人群一一夏河人. 考虑到距今约 700 900 万年前，人与猿走到揖别的岔路之后，世界范围 内出现了繁多的人类种群, 因此, 研究古蛋白质的学者有 望在更古老的人类遗址中, 找到更多携带幽灵基因的人群. 不仅如此, 对于旧石器时代遗址出土的化石而言, 由于埋 藏过程的影响, 一般能够完整保存下来的标本数量相对较 少, 这些破碎的化石在传统形态观察、种属鉴定、年龄统 计以及遗址古环境恢复方面的价值较为有限, 往往被束之 高阁，但是现有技术能够在海量的碎骨中简单、快速地读 取骨骼中的蛋白质信息, 篮选出漏网的人类遗骸, 从而扩 大了找到人类遗骸的化石标本的范围, 增加了找到新人群 的概率.

因为同源蛋白质氨基酸排列的相似程度代表了不同 人类种群之间的亲缘程度, 所以越来越多的学者认识到, 蛋白质序列所提供的系统发育信息可被用于研究古老人 群与现代人群之间的进化关系，画出生物之间的遗传距离 和演化图谱, 进而阐明人类演化关系, 追溯各个节点的人 类祖先.

2020 年 4 月, Nature (《自然》)杂志发表了参与夏河 丹尼索瓦人鉴定工作的 Welker 等人 ${ }^{[4]}$ 的研究成果. 此次被 研究的先驱人一般被认为是最早到达欧洲西部的人科成 员. 根据之前对骨骼、牙齿形态的研究, 研究者认为先驱 人既与尼安德特人有相似点, 同时具有部分早期现代人的 
特征, 这导致无法判断先驱人与直立人、尼安德特人以及 早期现代人的关系. 而在新的研究中, 研究者不但在牙齿 中提取到了古蛋白质组学信息, 并且将蛋白质序列与来自 格鲁吉亚的直立人、现代人的同类蛋白质进行比较, 进而 将先驱人安放到人类演化树上相应的位置, 即先驱人是后 来中晚更新世的古人类(包括现代人、尼安德特人和丹尼索 瓦人)的一个关系亲密的姐妹谱系.

不仅如此, 古蛋白质研究还能还原高分辨率的人体细 节. 例如, 编码牙齿釉原蛋白的基因恰好位于性染色体 $(\mathrm{X}$ 染色体和 $Y$ 染色体)上, 如果逆向思维, 直接检测嬏原蛋白 即可反推其对应的基因序列, 进而确定人类遗骸的性别, 近 年来在步氏巨猿、先驱人等研究中, 这项技术已经得到了运 用. 近期, 有学者分别检验了通过基因研究、传统的骨骼形 态研究及基于古蛋白质的性别研究的准确性, 证明古蛋白 质鉴定技术比基于 DNA 或骨骼解剖的技术更可靠 ${ }^{[5]}$.

虽然有些乐观的学者们认为, 未来古蛋白质组学有希
望为我们找到更多古人类的同时，甚至可以解锁整棵人类 演化树 ${ }^{[6]}$, 但是, 我们也不得不面对古蛋白质研究的局限 性. 首先, 正是由于蛋白质需要在生物体内发挥功能, 其 具有一定保守性，对于系统发育分析的分辨率不如 DNA. 其次, 古蛋白质研究与测年技术、古 DNA 研究一样, 面临 破坏人类标本的问题. 此外, 蛋白质种类繁多, 序列及结 构较 DNA 也更为复杂, 所以在实际操作中仍然困难重重. 例如, 蛋白质不能够像核酸序列一样扩增, 故检测灵敏度 有限, 对样本中蛋白质含量要求较高. 最后, 对于降解较 为严重的样本, 很难得到完整的肽段信息用于序列拼接.

因此, 若想要回答“我们从哪里来”的问题, 不论是通 过古 DNA 研究或者古蛋白质研究, 还是通过传统的人类 骨骼比较解剖手段, 都仍然需要相关领域的学者继续发展 面向古生物样本的新技术和新方法, 对遗留下来的古老牙 齿和碎骨进行多学科分析、多角度的上下求索, 这样才能 在未来为我们讲出更加丰富、更加准确的人类起源故事.

\section{推葆阅读文献}

1 Welker F, Ramos-Madrigal J, Kuhlwilm M, et al. Enamel proteome shows that Gigantopithecus was an early diverging pongine. Nature, 2019, 576: 262-265

2 Meyer M, Arsuaga J L, de Filippo C, et al. Nuclear DNA sequences from the Middle Pleistocene Sima de los Huesos hominins. Nature, 2016, 531: 504-507

3 Chen F, Welker F, Shen C C, et al. A late Middle Pleistocene Denisovan mandible from the Tibetan Plateau. Nature, 2019, 569: 409-412

4 Welker F, Ramos-Madrigal J, Gutenbrunner P, et al. The dental proteome of Homo antecessor. Nature, 2020, 580: 235-238

5 Buonasera T, Eerkens J, de Flamingh A, et al. A comparison of proteomic, genomic, and osteological methods of archaeological sex estimation. Sci Rep, 2020, 10: 1-15

6 Warren M. Move over, DNA: Ancient proteins are starting to reveal humanity's history. Nature, 2019, 570: 433 